\title{
The clinical value of measuring antiphospholipid antibodies in high risk primigravidae and nullipara, a case control study
}

\author{
Amr A. Mansy ${ }^{1 *}$, Nermeen N. Al-Gizawy², AbdEl-Latif Gaballah², \\ Noha El-Sawy ${ }^{2}$, Wessam AL-Gendi ${ }^{3}$
}

\begin{abstract}
${ }^{1}$ Department of Obstetrics and Gynecology, ${ }^{2}$ Department of Physical Medicine, Rheumatology and Rehabilitation, ${ }^{3}$ Department of Clinical and Chemical Pathology, Alexandria University, Egypt
\end{abstract}

Received: 10 October 2017

Accepted: 04 November 2017

*Correspondence:

Dr. Amr A. Mansy,

E-mail: amrmansy@gmail.com

Copyright: (c) the author(s), publisher and licensee Medip Academy. This is an open-access article distributed under the terms of the Creative Commons Attribution Non-Commercial License, which permits unrestricted non-commercial use, distribution, and reproduction in any medium, provided the original work is properly cited.

\begin{abstract}
Background: Antiphospholipid syndrome (APS) is an autoimmune thrombophilic condition that is marked by the presence in blood of antibodies that recognize and attack phospholipid-binding proteins, rather than phospholipid itself. The clinical manifestations of APS include vascular thrombosis and pregnancy complications, especially recurrent spontaneous miscarriages and, less frequently maternal thrombosis. Obstetric manifestations of APS are not restricted to fetal loss. Current APS criteria include preterm labour, oligohydramnios, neonatal complications as prematurity-estimated at 30-60\% and more common in SLE patients, intrauterine growth restriction "IUGR", fetal distress and rarely fetal or neonatal thrombosis, associated maternal obstetric complications as preeclampsia/eclampsia and HELLP syndrome, arterial or venous thrombosis and other aPL-related complications as placental insufficiency.

Methods: The study included 90 primigravida and nullipara during their first trimester antenatal care visits, divided into 2 groups after signing a well-informed consent to declare their willing to participate in the study. All selected cases and control group were subjected to demographic data, thorough history taking, clinical examination focused on arterial blood pressure, body mass index, laboratory investigations fasting and random blood glucose level, serum analysis of anti-phospholipid anti bodies by enzyme linked immunosorbent assay (ELISA) including anticardiolipin antibodies (ACL), anti $\beta 2$-glycoprotein I antibodies (Anti $\beta 2$ GPI) and citrated sample for lupus anticoagulant test (LA).

Results: We can conclude from the current study that aPLs namely lupus anticoagulant is significantly more common in high risk primigravidae having obesity, hypertension and diabetes mellitus than those without risk factors.

Conclusions: aPLs antibodies as lupus anticoagulant is significantly more common in high risk primigravidae having obesity, hypertension and diabetes mellitus than those without risk factors.
\end{abstract}

Keywords: Antiphospholipid, Nullipara, Primigravidae

\section{INTRODUCTION}

Antiphospholipid Syndrome (APS) is an autoimmune thrombophilic condition that is marked by the presence in blood of antibodies that recognize and attack phospholipid-binding proteins, rather than phospholipid itself. The clinical manifestations of APS include vascular thrombosis and pregnancy complications, especially recurrent spontaneous miscarriages and, less frequently maternal thrombosis. ${ }^{1}$ 
Presence of antiphospholipid antibody (APL) alone, in the absence of typical clinical complications, does not indicate a diagnosis of APS; long-term asymptomatic aPL-positive patients exist. When diagnosed in patients with underlying autoimmune disease (usually SLE), APS is termed secondary APS, while in otherwise healthy persons it is termed primary APS. Catastrophic Antiphospholipid syndrome (CAPS) represents the severe end of the spectrum with multiple organ thromboses in a rapid period of time. ${ }^{2}$

The clinical spectrum of this syndrome has widened, with important advances in the knowledge of its pathogenesis and clinical management made during the past several years. Like other autoimmune disorders, APS does not have a known etiology.

There are several hypotheses to explain the probable cause:

- Passive transfer of maternal antibodies mediates autoimmune disorders in the fetus and the newborn

- Familial occurrence of aPL has been reported, and suggested genetic associations. ${ }^{3}$

Antiphospholipid antibodies can be broadly categorized into those antibodies that prolong phospholipiddependent coagulation assays, known as lupus anticoagulants (LA), or anticardiolipin antibodies (aCL) which reduce the coagulant potential of the plasma and prolong the clotting time in coagulation tests based on the activated partial thromboplastin time. Consensus guidelines recommend screening for LA with 2 or more phospholipid-dependent coagulation tests. ${ }^{4}$

Types of patients with aPL antibodies:

- Antiphospholipid syndrome:

a. Primary - in absence of SLE

b. Secondary - in patients with SLE

- aPL antibodies stimulated by infection:

a. No known association with thrombosis (e.g., syphilis, Lyme disease, cytomegalovirus, Epstein-Barr virus)

b. Possible association with thrombosis (e.g., varicella, HIV, hepatitis C)

- Drug-induced aPL antibodies (e.g. chlorpromazine and other phenothiazines)

- $\quad$ aPL antibodies prevalent in the general population. ${ }^{5}$

Clinical manifestations include arterial thrombosis, venous thrombosis, and hematologic, cutaneous manifestations along with obstetric, neurologic, renal and cardiac complications and can include multisystem failure.

Obstetric manifestations of APS are not restricted to fetal loss. Current APS criteria include preterm labour, oligohydramnios, neonatal complications as prematurity- estimated at 30-60\% and more common in SLE patients, intrauterine growth restriction "IUGR", fetal distress and rarely fetal or neonatal thrombosis, associated maternal obstetric complications as pre-eclampsia/eclampsia and HELLP syndrome, arterial or venous thrombosis and other aPL-related complications as placental insufficiency. ${ }^{6}$

The primary objective of the study is to study the serum level of anti-phospholipids Antibodies (APLAs) in high risk diabetic, hypertensive and obese primigravidae.

The secondary objective is to investigate the value of routine thrombo prophylaxis in high risk diabetic, hypertensive and obese primigravidae.

\section{METHODS}

The study was conducted in the antenatal clinic of ElShatby Obstetrics and Gynecology University Hospital in Alexandria.

Ethical approval for the study was obtained from the Ethical Committee of the Alexandria Faculty of Medicine. The study included 90 primigravida and nullipara during their first trimester antenatal care visits, divided into 2 groups after signing a well-informed consent to declare their willing to participate in the study

Group A: age from 20-35 years. forty-five (45) cases have one or more of the following maternal risk factors:

- Diabetes mellitus (fasting plasma glucose level $\geq 126$ $\mathrm{mg} / \mathrm{d}$ or plasma glucose $\geq 200 \mathrm{mg} / \mathrm{dl}$ two hours after a $75 \mathrm{~g}$ oral glucose load as in a glucose tolerance test)

- Obesity (body mass index $\geq 30 \mathrm{~kg} / \mathrm{m}^{2}$ )

- Hypertension (resting systemic systolic blood pressure $\geq 140 \mathrm{mmHg}$ and/or diastolic $\geq 90 \mathrm{mmHg}$ measured in more than one occasion).

Group B: Age from 20-35 years. Forty-five (45) primigravidae and nullipara in the first trimester with no risk factors were recruited as a control group and were compared with the study group regarding age, BMI, FBS, PPBS, blood pressure and aPL.

Considering the prevalence of antiphospholipid among normal population accounting for about $3 \%$ required sample size was calculated using Epi Info (version 7).

All selected cases and control group were subjected to:

- Demographic data,

- Thorough history taking focused on history of associated risk factors as DM, hypertension, heart disease, renal disease, autoimmune disease, alcohol intake, smoking, drug history, history of thromboembolic complications and finally family 
history of recurrent miscarriages, infertility or presence of autoimmune diseases

- Clinical examination focused on:
a) Arterial blood pressure
b) Body mass index (BMI) will be calculated: Body weight $(\mathrm{Kg}) /$ height $\left(\mathrm{m}^{2}\right)$.

- Laboratory investigations:

a) Fasting and random blood glucose level

b) Serum analysis of anti-phospholipid anti-bodies by enzyme linked immunosorbent assay (ELISA) including:

$\begin{aligned} \text { i. } & \text { Anticardiolipin antibodies (ACL) } \\ \text { ii. } & \text { Anti } \beta 2 \text {-glycoprotein I antibodies (Anti } \beta 2 \\ \text { iii. } & \text { GPI) }\end{aligned}$

iii. Citrated sample for lupus anticoagulant test
(LA).

\section{Analysis of antiphospholipid antibodies}

In a normal range study with samples from healthy blood donors the following ranges have been established with this Alegria assay.,8

\section{Expected values for IgM antibodies}

- $\quad$ Normal $<7$ MPL U/ml

- $\quad$ Elevated $\geq 7 \mathrm{MPL} \mathrm{U} / \mathrm{ml}$

Expected values for $\operatorname{Ig} G$ antibodies

- $\quad$ Normal $<10 \mathrm{GPL} \mathrm{U} / \mathrm{ml}$

- $\quad$ Elevated $\geq 10 \mathrm{GPL} \mathrm{U/ml}$

Detection of anti $\beta 2$-glycoprotein I antibodies (anti $\beta 2$ GPI)

The accepted range was:

- Positive: anti $\beta 2$ GPI IgG $\geq 10 \mathrm{IU} / \mathrm{mL}$

- Negative: anti $\beta 2$ GPI IgG $<10 \mathrm{IU} / \mathrm{mL}$

Detection of Lupus anticoagulants (LAs)

Expected values

- If ratio LA1 screening / LA2 confirm is greater than 2.0 LA is strongly present

- If ratio LA1 screening / LA2 confirm is between 1.5 and 2 LA is moderately present

- If ratio LA1 screening / LA2 confirm is between 1, 2 and $1.5 \mathrm{LA}$ is weakly present.

\section{RESULTS}

\section{Risk factors in the study group}

Among the study group 29 cases had no other risk factors, 11 were exposed to passive smoking, 2 had rheumatic heart disease and 3 cases were pregnant after induction of ovulation (Table 1).

Table 1: Distribution of the studied cases according to presence of other risk factors in high risk group $(n=45)$.

\begin{tabular}{lll} 
Other risk factor & No. & $\%$ \\
None & 29 & 64.4 \\
\hline Passive smoker & 11 & 24.4 \\
\hline Rheumatic heart disease & 2 & 4.4 \\
\hline Ovulation induction & 3 & 6.7
\end{tabular}

\section{Lupus anticoagulant (LA) in the studied groups}

LA was present in 10 cases among the high-risk group presenting $22.2 \%$ of the group, while it was just suspected in only one case of the control group, that was statistically significant with a $\mathrm{p}=0.001$ (Table 2 ).

Table 2: Comparison between the two studied groups according to LA.

\begin{tabular}{|c|c|c|c|c|c|}
\hline & \multicolumn{2}{|c|}{$\begin{array}{l}\text { Cases } \\
(\mathrm{n}=45)\end{array}$} & \multicolumn{2}{|c|}{$\begin{array}{l}\text { Control } \\
(\mathrm{n}=45)\end{array}$} & \multirow[t]{2}{*}{ p } \\
\hline & No. & $\%$ & No. & $\%$ & \\
\hline \multicolumn{6}{|l|}{ LA } \\
\hline Absent & 35 & 77.8 & 44 & 97.8 & \multirow{3}{*}{$0.001^{*}$} \\
\hline Present & 10 & 22.2 & 0 & 0.0 & \\
\hline Suspected & 0 & 0.0 & 1 & 2.2 & \\
\hline \multicolumn{6}{|l|}{ LA 1 (seconds) } \\
\hline Min-Max & \multicolumn{2}{|c|}{$31.0-60.0$} & \multicolumn{2}{|c|}{$31.0-44.0$} & \multirow{3}{*}{0.190} \\
\hline Mean \pm SD & \multicolumn{2}{|c|}{$38.76 \pm 7.05$} & \multicolumn{2}{|c|}{$37.28 \pm 2.44$} & \\
\hline Median & \multicolumn{2}{|c|}{37.10} & \multicolumn{2}{|c|}{37.70} & \\
\hline LA 2 (seconds) & \multicolumn{2}{|c|}{$(n=10)$} & \multicolumn{2}{|c|}{$(\mathbf{n}=\mathbf{1})^{\#}$} & \\
\hline Min-Max & \multicolumn{2}{|c|}{$33.30-37.90$} & & \multirow{3}{*}{-} \\
\hline Mean \pm SD. & 35.9 & \pm 1.43 & \multirow{2}{*}{\multicolumn{2}{|c|}{40.0}} & \\
\hline Median & \multicolumn{2}{|c|}{36.20} & & & \\
\hline
\end{tabular}

As regard LA1, its mean time in the high-risk group was $38.76 \pm 7.05$ seconds which showed no statistical significant difference from that of the control group. (Table 2)

The mean time of LA2 which was done in 10 cases of the high-risk group was $35.94 \pm 1.43$ seconds; this was not compared with the control group because it was done in only one case in this group (Table 2).

LA was present in 6 cases of the obese group presenting $25 \%$ of the group, in 2 cases of the diabetic group presenting $20 \%$ of the group and in 2 cases of the hypertensive group presenting $18.2 \%$ of the group. This difference was statically significant when comparing each subgroup with the control group but not significant between the three subgroups (Table 3 ). 
Table 3: Comparison between the different studied groups according to LA.

\begin{tabular}{|c|c|c|c|c|c|c|c|}
\hline & \multicolumn{4}{|l|}{ Cases $(n=45)$} & \multicolumn{2}{|c|}{ Control } & \multirow[t]{3}{*}{ p } \\
\hline & Obese & \multicolumn{2}{|c|}{ Diabetic } & HTN & & \\
\hline & No. & No. & $\%$ & No. & & $\%$ & \\
\hline LA & $(n=24)$ & $(\mathbf{n}=$ & & $(n=11)$ & $(n=$ & & \\
\hline Negative & 75.0 & 8 & 80.0 & 81.8 & 44 & 97.8 & \multirow{3}{*}{$0.003^{*}$} \\
\hline Positive & 25.0 & 2 & 20.0 & 18.2 & 0 & 0.0 & \\
\hline Suspected & 0.0 & 0 & 0.0 & 0.0 & 1 & 2.2 & \\
\hline $\mathbf{P}_{\text {control }}$ & ${ }^{\mathrm{MC}} \mathrm{p}=0.002^{*}$ & \multicolumn{2}{|c|}{${ }^{\mathrm{MC}} \mathrm{p}=0.027^{*}$} & ${ }^{\mathrm{MC}} \mathrm{p}=0.037^{*}$ & & & \\
\hline \multicolumn{8}{|c|}{ Significance between groups ${ }^{\mathrm{FE}} \mathrm{p}_{1}=1.000,{ }^{\mathrm{FE}} \mathrm{p}_{2}=1.000,{ }^{\mathrm{FE}} \mathrm{p}_{3}=1.000$} \\
\hline LA 1 & $(n=24)$ & \multicolumn{2}{|c|}{$(\mathbf{n}=10)$} & $(\mathbf{n}=11)$ & \multicolumn{2}{|c|}{$(n=45)$} & \\
\hline Min-Max & $31.0-54.60$ & \multicolumn{2}{|c|}{$31.0-60.0$} & $31.0-56.30$ & \multicolumn{2}{|c|}{$31.0-44.0$} & \multirow{3}{*}{0.438} \\
\hline Mean \pm SD & $38.56 \pm 6.05$ & \multicolumn{2}{|c|}{$40.16 \pm 9.08$} & $37.93 \pm 7.60$ & \multicolumn{2}{|c|}{$37.28 \pm 2.44$} & \\
\hline Median & 37.0 & \multicolumn{2}{|c|}{38.10} & 34.90 & \multicolumn{2}{|c|}{37.70} & \\
\hline LA 2 & $(n=6)$ & \multicolumn{2}{|c|}{$(\mathbf{n}=2)$} & $(n=2)$ & \multicolumn{2}{|c|}{$(\mathbf{n}=1)^{\#}$} & \\
\hline Min-Max & $33.30-37.30$ & \multicolumn{2}{|c|}{$34.0-35.10$} & \multirow{2}{*}{$\begin{array}{l}36.10-37.90 \\
37.0 \pm 1.27\end{array}$} & & & \\
\hline Mean \pm SD & $36.05 \pm 1.42$ & 34.5 & & & \multicolumn{2}{|c|}{40.0} & 0.195 \\
\hline Median & 36.30 & 34.5 & & 37.0 & & & \\
\hline
\end{tabular}

MCp: $\mathrm{p}$ value for Monte Carlo for Chi square test for comparing between the two groups

There was no statistical significance difference in the LA1 and LA2 times between the three subgroups and between each of them and the control group (Table 3 ).

\section{Anti B2-glycoprotein I IgG antibodies (Anti B2 GPI IgG) in the study groups}

Anti $\beta 2$ GPI IgG was negative in $100 \%$ of cases of both high-risk group and control group (Table 4).

The mean level of Anti $\beta 2$ GPI in the high-risk group was $1.23 \pm 1.35 \mathrm{IU} / \mathrm{mL}$ in the high-risk group which was significantly higher than its mean level in the control group which was $0.74 \pm 0.45 \mathrm{IU} / \mathrm{mL}$ with $\mathrm{p}=0.002$ (Table 4). There was no statistically significant difference in anti $\beta 2$ GPI IgG level between the three subgroups nor between the diabetic group and the control group (Table
5). Anti $\beta 2$ GPI IgG level was significantly higher in obese group and hypertensive group when compared to the control group with $\mathrm{p}=0.002$ and 0.049 subsequently (Table 5).

Table 4: Comparison between the two studied groups according to Anti $\beta 2$ GPI IgG.

\begin{tabular}{|c|c|c|c|c|c|}
\hline \multirow{2}{*}{$\begin{array}{l}\text { Anti } \beta 2 \text { GPI } \\
\operatorname{IgG}(I U / m L)\end{array}$} & \multicolumn{2}{|c|}{$\begin{array}{l}\text { Cases } \\
(n=45)\end{array}$} & \multicolumn{2}{|c|}{$\begin{array}{l}\text { Control } \\
(\mathrm{n}=45)\end{array}$} & \multirow{2}{*}{ p } \\
\hline & No. & $\%$ & No. & $\%$ & \\
\hline Negative & 45 & 100.0 & 45 & 100.0 & \\
\hline Positive & 0 & 0.0 & 0 & 0.0 & \\
\hline Min-Max & \multicolumn{2}{|c|}{$0.30-7.50$} & \multicolumn{2}{|c|}{$0.30-1.70$} & \multirow{3}{*}{$0.002^{*}$} \\
\hline Mean \pm SD & \multicolumn{2}{|c|}{$1.23 \pm 1.35$} & \multicolumn{2}{|c|}{$0.74 \pm 0.45$} & \\
\hline Median & \multicolumn{2}{|c|}{0.80} & \multicolumn{2}{|c|}{0.50} & \\
\hline
\end{tabular}

Table 5: Comparison between the different studied groups according to Anti $\beta 2$ GPI IgG.

\begin{tabular}{|c|c|c|c|c|c|c|c|c|c|}
\hline \multirow{3}{*}{$\begin{array}{l}\text { Anti } \beta 2 \text { GPI } \\
\text { IgG (IU/mL) }\end{array}$} & \multicolumn{6}{|c|}{ Cases $(n=45)$} & \multirow{2}{*}{\multicolumn{2}{|c|}{$\begin{array}{l}\text { Control } \\
(\mathrm{n}=45)\end{array}$}} & \multirow{3}{*}{ p } \\
\hline & \multicolumn{2}{|c|}{$\begin{array}{l}\text { Obese } \\
(n=24)\end{array}$} & \multicolumn{2}{|c|}{$\begin{array}{l}\text { Diabetic } \\
(n=10)\end{array}$} & \multicolumn{2}{|c|}{$\begin{array}{l}\text { HTN } \\
(n=11)\end{array}$} & & & \\
\hline & No. & $\%$ & No. & $\%$ & No. & $\%$ & No. & $\%$ & \\
\hline Negative & 24 & 100.0 & 10 & 100.0 & 11 & 100.0 & 45 & 100.0 & \\
\hline Positive & 0 & 0.0 & 0 & 0.0 & 0 & 0.0 & 0 & 0.0 & - \\
\hline Min-Max & 0.50 & & 0.30 & & 0.50 & & 0.30 & & \\
\hline Mean \pm SD. & 1.38 & & 0.74 & & 1.33 & & 0.74 & & $0.010^{*}$ \\
\hline Median & 0.90 & & 0.80 & & 0.70 & & 0.50 & & \\
\hline $\mathrm{P}_{\text {control }}$ & 0.00 & & 0.43 & & 0.04 & & & & \\
\hline
\end{tabular}


There was no significant correlation between Anti $\beta 2$ GPI IgG level and BMI, FBS, PPBS, systolic blood pressure and diastolic blood pressure values in the high-risk group (Table 6).

\section{Anti-cardiolipin antibodies in the studied groups}

Anti-cardiolipin IgM antibodies were negative in $100 \%$ of cases of both high risk and control groups (Table 6).

The mean level of anti-cardiolipin IgM antibodies among high risk group was $1.1 \pm 0.91 \mathrm{MPL} / \mathrm{ml}$ which was not significantly different from that of the control group which was $1.01 \pm 0.54 \mathrm{MPL} / \mathrm{ml}$ (Table 6).

There was no statistically significant difference in the mean level of anti-cardiolipin IgM antibodies between the three subgroups and between them and the control group (Table 7).

Table 6: Comparison between the two studied groups according to Anti-cardiolipin-IgM antibodies

\section{(MPL/mL).}

\begin{tabular}{|c|c|c|c|c|c|}
\hline \multirow{2}{*}{$\begin{array}{l}\text { Anti- } \\
\text { cardiolipin- } \\
\text { IgM abs } \\
\text { (MPL/mL) }\end{array}$} & \multicolumn{2}{|c|}{$\begin{array}{l}\text { Cases } \\
(n=45)\end{array}$} & \multicolumn{2}{|c|}{$\begin{array}{l}\text { Control } \\
(n=45)\end{array}$} & \multirow{2}{*}{ p } \\
\hline & No. & $\%$ & No. & $\%$ & \\
\hline Negative & 45 & 100.0 & 45 & 100.0 & \multirow{2}{*}{ - } \\
\hline Positive & 0 & 0.0 & 0 & 0.0 & \\
\hline Min-Max & \multicolumn{2}{|c|}{$0.50-5.20$} & \multicolumn{2}{|c|}{$0.60-2.60$} & \multirow{3}{*}{0.704} \\
\hline Mean \pm SD. & \multicolumn{2}{|c|}{$1.10 \pm 0.91$} & \multicolumn{2}{|c|}{$1.01 \pm 0.54$} & \\
\hline Median & \multicolumn{2}{|c|}{0.80} & \multicolumn{2}{|c|}{0.80} & \\
\hline
\end{tabular}

Table 7: Comparison between the different studied groups according to anti-cardiolipin-IgM (MPL/mL).

\begin{tabular}{|c|c|c|c|c|c|c|c|c|c|}
\hline \multirow{3}{*}{$\begin{array}{l}\text { Anti-cardiolipin- } \\
\text { IgM (MPL/mL) }\end{array}$} & \multicolumn{6}{|c|}{ Cases $(n=45)$} & \multirow{2}{*}{\multicolumn{2}{|c|}{$\begin{array}{l}\text { Control } \\
(\mathrm{n}=45)\end{array}$}} & \multirow{3}{*}{$\mathbf{p}$} \\
\hline & \multicolumn{2}{|c|}{ Obese $(n=24)$} & \multicolumn{2}{|c|}{ Diabetic $(n=10)$} & \multicolumn{2}{|c|}{ HTN $(n=11)$} & & & \\
\hline & No. & $\%$ & No. & $\%$ & No. & $\%$ & No. & $\%$ & \\
\hline Negative & 24 & 100.0 & 10 & 100.0 & 11 & 100.0 & 45 & 100.0 & \multirow{2}{*}{-} \\
\hline Positive & 0 & 0.0 & 0 & 0.0 & 0 & 0.0 & 0 & 0.0 & \\
\hline Min-Max & \multicolumn{2}{|c|}{$0.50-5.20$} & \multicolumn{2}{|c|}{$0.60-1.10$} & \multicolumn{2}{|c|}{$0.60-1.10$} & \multicolumn{2}{|c|}{$0.60-2.60$} & \multirow{3}{*}{0.255} \\
\hline Mean \pm SD & \multicolumn{2}{|c|}{$1.37 \pm 1.19$} & \multicolumn{2}{|c|}{$0.77 \pm 0.16$} & \multicolumn{2}{|c|}{$0.82 \pm 0.18$} & 1.01 & & \\
\hline Median & \multicolumn{2}{|c|}{0.95} & \multicolumn{2}{|c|}{0.80} & \multicolumn{2}{|l|}{0.80} & \multicolumn{2}{|c|}{0.80} & \\
\hline
\end{tabular}

The mean level of Anti-cardiolipin IgG antibodies among high risk group was $2.69 \pm 1.1 \mathrm{GPL} / \mathrm{ml}$ which was significantly lower than that of the control group which was $2.89 \pm 0.67 \mathrm{GPL} / \mathrm{ml}$ (Table 8$)$.

Table 8: Comparison between the two studied groups according to anti-cardiolipin-IgG (GPL/MI).

\begin{tabular}{|c|c|c|c|c|c|}
\hline \multirow{2}{*}{$\begin{array}{l}\text { Anti- } \\
\text { cardiolipin- } \\
\text { IgG (GPL/MI) }\end{array}$} & \multicolumn{2}{|c|}{$\begin{array}{l}\text { Cases } \\
(n=45)\end{array}$} & \multicolumn{2}{|c|}{$\begin{array}{l}\text { Control } \\
(\mathrm{n}=45)\end{array}$} & \multirow{2}{*}{ p } \\
\hline & No. & $\%$ & No. & $\%$ & \\
\hline Negative & 45 & 100.0 & 45 & 100.0 & \multirow{2}{*}{ - } \\
\hline Positive & 0 & 0.0 & 0 & 0.0 & \\
\hline Min-Max & \multicolumn{2}{|c|}{$1.50-6.50$} & \multicolumn{2}{|c|}{$2.10-4.0$} & \multirow{3}{*}{$0.030^{*}$} \\
\hline Mean \pm SD & \multicolumn{2}{|c|}{$2.69 \pm 1.10$} & \multicolumn{2}{|c|}{$2.89 \pm 0.67$} & \\
\hline Median & \multicolumn{2}{|c|}{2.40} & \multicolumn{2}{|c|}{2.70} & \\
\hline
\end{tabular}

\section{DISCUSSION}

In the current study LA was detected in 10 cases among the high-risk group presenting $22.2 \%$ of the group, while it was just suspected in only one case of the control group, that was statistically significant with a $\mathrm{p}=0.001$. As regard LA1, its mean time in the high-risk group was $38.76 \pm 7.05$ seconds which showed no statistical significant difference from that of the control group.
The mean time of LA2 which was done in 10 cases of the high-risk group was $35.94 \pm 1.43$ seconds; this was not compared with the control group because it was done in only one case in this group.

LA was present in 6 cases of the obese group presenting $25 \%$ of the group, in 2 cases of the diabetic group presenting $20 \%$ of the group and in 2 cases of the hypertensive group presenting $18.2 \%$ of the group. This difference was statistically significant when comparing each subgroup with the control group but not significant between the three subgroups.

There was no statistical significance difference in the LA1 and LA2 times between the three subgroups and between each of them and the control group.

Boddi el al detected LA positive in $34 \%$ of a group of insulin dependent diabetes mellitus pregnant females comparable to $20 \%$ of the diabetic group in the current study. He also detected poorer obstetric outcome in the form of pregnancy induced hypertension and intrauterine growth restriction in the positive group more than the negative one. ${ }^{9}$

Rollino et al detected LA in $8 \%$ of a group of people having essential hypertension comparable to $18 \%$ in the 
current study. ${ }^{10}$ Also, Loukidi et al reported positive LA only in hypertensive females in a study done over obese, hypertensive and normal pregnant females. ${ }^{11}$

Gary et al reported positive antiphospholipid antibodies in $15.7 \%$ of a group of obese population having venous thromboembolism which is comparable to $25 \%$ detected in the obese group in the current study. ${ }^{12}$

Among the 10 LA present cases, 7 cases were weakly present, 3 cases were moderately present, and 0 cases were strongly present. Moffat et al stated that there is no correlation between the "strength" of lupus anticoagulants and the level of thrombotic risk; thus, it is important to identify both "weak" and "strong" lupus anticoagulants. ${ }^{13}$

Anti $\beta 2$ GPI IgG was negative in $100 \%$ of cases of both high-risk group and control group but the mean level of Anti $\beta 2$ GPI in the high-risk group was $1.23 \pm 1.35 \mathrm{IU} / \mathrm{mL}$ in the high-risk group which was significantly higher than its mean level in the control group which was $0.74 \pm 0.45$ $\mathrm{IU} / \mathrm{mL}$ with $\mathrm{p}=0.002$ denoting it is was high normal level in the high-risk group. There was no statistically significant difference in Anti $\beta 2$ GPI IgG level between the three subgroups nor between the diabetic group and the control group, but it was significantly higher in obese group and hypertensive group when compared to the control group with $\mathrm{p}=0.002$ and 0.049 subsequently suggesting high normal level in both subgroups.

Boroges et al reported no significant difference in presence of Anti $\beta 2$ GPI IgG between cases and controls in a study done on patients having diabetes and hypertension. ${ }^{14}$

Valdes-Macho et al also reported no significant difference in a study conducted on 125 hypertensive pregnant females. ${ }^{15}$

Marchetti et al reported no association between Anti $\beta 2$ GPI IgG and non-severe pre-eclampsia, but reported a significant association in cases of severe pre-eclampsia. ${ }^{16}$ Rezk et al stated that there was no significant relation between Anti $\beta 2$ GPI and development of pre-eclampsia, but its presence is an independent risk factor of pregnancy loss. ${ }^{17}$

Anti-cardiolipin antibodies were negative in $100 \%$ of cases of both high risk and control groups with no significant difference in mean levels between both study groups nor between the three subgroups and the control groups except for the mean level of Anti-cardiolipin IgG antibodies among high risk group which was significantly lower than that of the control group suggesting higher but still normal level in the control group.

There was no significant correlation between Anticardiolipin IgG level and BMI, FBS, PPBS, systolic blood pressure and diastolic blood pressure values in the high-risk group, while anti-cardiolipin IgM showed significant positive correlation only with BMI in the high-risk group suggesting increase in level despite still being normal with increase in BMI.

Boroges et al also reported no significant difference in presence of Anti-cardiolipin antibodies between cases and controls in the study mentioned before. ${ }^{14}$ while Valdes-Macho et al also reported no significant difference in the previously mentioned study. ${ }^{15}$

In the current study antiphospholipid antibodies were detected in 10 cases among the high-risk group presenting $22.2 \%$ of the group, while it was just suspected in only one case of the control group, that was statistically significant with a $\mathrm{p}=0.001$. All of the positive cases had lupus anticoagulant; none of the cases had neither Anti-cardiolipin nor Anti $\beta 2$ GPI antibodies.

\section{CONCLUSION}

aPLs antibodies as lupus anticoagulant is significantly more common in high risk primigravidae having obesity, hypertension and diabetes mellitus than those without risk factors.

Funding: No funding sources Conflict of interest: None declared

Ethical approval: The study was approved by the Institutional Ethics Committee

\section{REFERENCES}

1. Negrini S, Pappalardo F, Murdaca G, Indiveri F, Puppo F. The antiphospholipid syndrome: from pathophysiology to treatment. Clinical and Experimental Medicine. 2017;17(3):257-67.

2. Cabrera CDM, Rodriguez-Jaimes C, AcevedoGallegos S, Gallardo-Gaona JM, Velazquez-Torres B, Ramirez-Calvo JA. Controversies concerning the antiphospholipid syndrome in obstetrics. Reumatologia clinica. 2017;13(1):30-6.

3. Levine JS, Branch DW, Rauch J. The antiphospholipid syndrome. New Eng J Med. 2002;346(10):752-63.

4. de Groot PG, Lutters B, Derksen RH, Lisman T, Meijers JC, Rosendaal FR. Lupus anticoagulants and the risk of a first episode of deep venous thrombosis. J Thrombosis Haemostasis. 2005;3(9):1993-7.

5. Tektonidou MG, Laskari K, Panagiotakos DB, Moutsopoulos HM. Risk factors for thrombosis and primary thrombosis prevention in patients with systemic lupus erythematosus with or without antiphospholipid antibodies. Arthritis Rheumatism. 2009;61(1):29-36.

6. Bremme KA. Haemostatic changes in pregnancy. Best Practice Res Clin Haematol. 2003;16(2):153-68.

7. Pierangeli SS, Favaloro EJ, Lakos G, Meroni PL, Tincani A, Wong RC, et al. Standards and reference materials for the anticardiolipin and antibeta2glycoprotein I assays: a report of 
recommendations from the APL task force at the $13^{\text {th }}$ International Congress on Antiphospholipid Antibodies. Int J Clin Chem. 2012;413(1-2):358-60.

8. Pengo V, Tripodi A, Reber G, Rand JH, Ortel TL, Galli M, et al. Update of the guidelines for lupus anticoagulant detection. Subcommittee on lupus anticoagulant/antiphospholipid antibody of the scientific and standardisation committee of the International Society on Thrombosis and Haemostasis. J Thrombosis Haemostasis. 2009;7(10):1737-40.

9. Boddi M, Prisco D, Fedi S, Cellai AP, Liotta AA, Parretti E, et al. Antiphospholipid antibodies and pregnancy disorders in women with insulin dependent diabetes. Thrombosis Res. 1996;82(3):207-16.

10. Rollino C, Boero R, Elia F, Montaruli B, Massara C, Beltrame G, et al. Antiphospholipid antibodies and hypertension. Lupus. 2004;13(10):769-72.

11. Loukidi B, Merzouk H, Merzouk SA, Malti N, Taouli K, Belarbi B, et al. Thrombosis factors and oxidant/antioxidant markers in obese and hypertensive women during pregnancy. Blood Pressure. 2015;24(4):242-9.

12. Gary T, Belaj K, Bruckenberger R, Hackl G, Hafner F, Froehlich H, et al. Primary antiphospholipid antibody syndrome-one further aspect of thrombophilia in overweight and obese patients with venous thromboembolism. Obesity (Silver Spring, Md). 2013;21(9):E463-6.
13. Moffat K, Raby A, Crowther M. Lupus anticoagulant testing. Methods in molecular biology (Clifton, NJ). 2013;992:97-108.

14. Borges RB, Bodanese LC, Muhlen CA, Repetto G, Viehe M, Norman GL, et al. Anti-beta2-glycoprotein I autoantibodies and metabolic syndrome. Brazilian Cardiol Arch. 2011;96(4):272-6.

15. Valdes-Macho E, Cabiedes J, Villa AR, Cabral AR, Alarcon-Segovia D. Anticardiolipin and anti-beta2glycoprotein-I antibodies in hypertensive disorders of pregnancy. Arch Med Res. 2002;33(5):460-5.

16. Marchetti T, de Moerloose P, Gris JC. Antiphospholipid antibodies and the risk of severe and non-severe pre-eclampsia: the NOHA casecontrol study. J Thrombosis Haemostasis. 2016;14(4):675-84.

17. Rezk M, Dawood R, Badr H. Maternal and fetal outcome in women with antiphospholipid syndrome: a three-year observational study. J Maternal-Fetal Neonatal Med. 2016;29(24):4015-9.

Cite this article as: Mansy AA, Al-Gizawy NN, Gaballah A, El-Sawy N, AL-Gendi W. The clinical value of measuring antiphospholipid antibodies in high risk primigravidae and nullipara, a case control study. Int J Reprod Contracept Obstet Gynecol 2017;6:5198-204. 